\title{
Recorridos urbanos. La Buenos Aires de Roberto Arlt y Juan Carlos Onetti
}

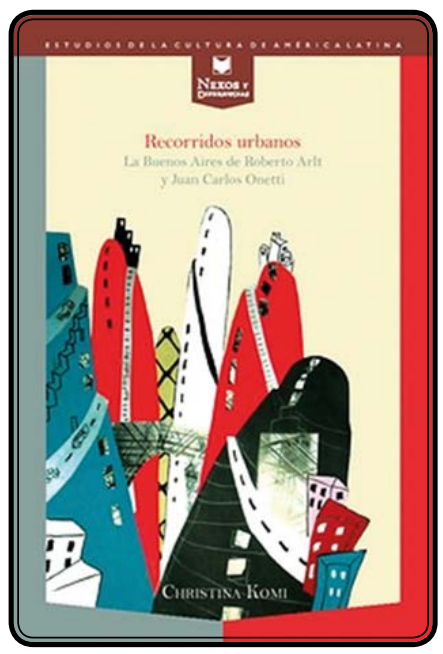

Christina Komi. 2009. Recorridos urbanos. La Buenos Aires de Roberto Arlt y Juan Carlos Onetti. Madrid: Editorial Iberoamericana.

Y las ciudades están como las prostitutas enamoradas de sus rufianes y de sus bandidos. Esto no puede seguir así.

Roberto Arlt

Desde el punto de vista del urbanismo y la arquitectura, el espacio urbano se define como la organización material del espacio, el modo en que las construcciones ocupan un lugar y es estilo particular de cada una de ellas. Sin embargo, la ciudad no es sólo un espacio construido ni se puede reducir a una serie de datos demográficos. Una simple aglomeración de calles, casas y personas no bastan para formar una ciudad, ya que para eso haría falta un modo de vida particular.

Una ciudad puede condicionar cierta manera de habitar, circular, vestirse, hablar determinados lenguajes, comportarse. El modo de ser en el espacio es un parámetro esencial para la definición de éste. Spengler en La decadencia de Occidente afirmaba que lo que distingue a la ciudad del pueblo no es su extensión ni su número de habitantes, sino la emergencia del alma urbana: «La naissance de l'âme d'une ville est proprement le prodige [...] Âme collective d'espèce entièrement nouvelle, dont les raisons dernières resteront toujours pour nous une éternelle énigme, elle surgit tout à coup et se sépare du psychisme général de sa culture» (1976 [1919]: 85).

La ciudad es un ser histórico que condensa la trayectoria cultural de una civilización. En la historia, el paso de un tipo de ciudad a otro coincide con el paso de un modo de percepción del mundo, a otro. Las construcciones materiales no desaparecen tan pronto como cambia el modo de percibir el mundo, sino que permanecen más allá del modo de vida o de las mentalidades que les permitieron nacer; por eso la ciudad es, metafóricamente, un tipo de palimpsesto que acumula sucesivamente los vestigios del pasado.

Para establecer la relación entre el espacio y su atmósfera, para determinar la relación entre ciudad como espacio construido y la 
ciudad como espacio social y conjunto de mentalidades $^{1}$ sería necesario un método o una semiótica urbana, para poder descifrar el lenguaje arquitectónico, el lenguaje de la piedra, y para tener acceso a la significación social de la estructura de un espacio urbano determinado. Falta otro método más para interpretar el lenguaje de sus habitantes, hecho de palabras, gestos, costumbres y actitudes. Ambos lenguajes tienen su propia lógica; representan y crean realidades. Nuestra tarea no es la de descifrar el lenguaje de un espacio urbano exterior, es decir, de una ciudad determinada entendida como realidad arquitectónica o sociológica, sino la de abordar este espacio desde el punto de vista de su reconstrucción ficcional; descubrir la ciudad representada, imaginada parcial o totalmente inventada, como en el caso de una pintura, que no es menos verdadera que la «rreal $»$.

La ciudad de la ficción no está hecha de colores, sino de palabras, Jacques Yves Tadié sugiere que entre estos dos modos de representación hay más semejanzas de lo que uno piensa, sobre todo cuando la diferencia se traduce en términos de distancia:

Si la peinture est la trace de l'espace représentatif, la littérature introduit une distance supplémentaire, parce que les signes du langage représentent la représentation. Ils notent un tableau, et c'est bien le nom d'une figure de discours de la rhétorique classique; on est, certes, tenté d'opposer la saisie globale de la perception picturale à la succession de la lecture; mais, outre que, du point de vue de l'artiste, cette opposition disparaît, puisque certains peintres mettent aussi longtemps à produire un tableau que l'écrivain un texte, regarder un tableau, c'est refaire un parcours dynamique, et l'invention instantanée n'est qu'illusion de spectateur superficiel (Tadié 1997 47-48).
Nuestro interés se centra en la ciudad del texto, narrada o fundada por la escritura, que, como se señala en la cita anterior, no es otra cosa que el conjunto de signos que constituyen un modo de representación de lo real.

\section{La ciudad análoga}

A través de los siglos, la ciudad ha sido objeto de representación de acuerdo con distintas lógicas estructurales y convenciones estéticas que, según la época y el contexto, prescribían la forma de lo imaginado, La representación de la ciudad se inscribe en el contexto más amplio de la representación de lo real dictado por las prácticas pictóricas y discursivas de los distintos momentos históricos. Esta representación revela una manera de ver y de percibir el mundo. Cada uno de sus discursos produce un orden espacial específico, una imagen de la ciudad que capta cómo se percibe el presente y comporta una combinación particular de elementos reales e imaginarios. La imagen de la ciudad es el resultado de todo un entramado de representaciones y resulta productiva en doble sentido ya que por un lado es producida por la ciudad y, a la vez, esta imagen misma produce nuevas significaciones y nuevos modos de entender la ciudad. Memoria, percepción e imagen conducen en una etapa ulterior a la capacidad de imaginación que nace de lo concreto (Rossi 1981).

Para poner de relieve la interacción particular entre el espacio en cuanto valor formalgeométrico y las significaciones que produce su precepción, evocamos aquí el concepto de «ciudad análoga» que nos invita a poner en duda la ciudad como realidad en un sentido convencional. Este concepto, creado por Aldo Rossi (1981), surgió de su estudio sobre grabados

1 Michel de Certeau establece una distinción entre el concepto de «espacio» y el de «lugar». Observa que el lugar designa un orden homogéneo y fijo de cosas, mientras que el espacio comporta elementos de movilidad, velocidad y dirección con lo cual funciona como «unité polyvalente de programmes conflictuels ou de proximités contractuelles». Más explícitamente dice que : «Un lieu est [...] la configuration instantanée de positions. Il implique une indication de stabilité. Il y a espace dès qu'on prend en considération des vecteurs de direction, des quantités de vitesse et la variable de temps. L'espace est un croisement de mobiles. Il est en quelque sorte animé par l'ensemble des mouvements qui s'y déploient > (De Certeau 1990: 173). 
y pinturas italianas del siglo XVI que, en su intento por representar una ciudad, combinaban totalmente la índole de la ciudad representada. La expresión señala el punto de encuentro entre los componentes materiales del espacio, la memoria y los elementos imaginativos que forjan, también a su manera, este espacio. El ejemplo que utiliza Rossi para explicar cómo surge esta noción es el Capricho de Canaletto sobre el Ponte de Rialto (1755-1759), grabado en el cual la ciudad de Venecia aparece como un ensamblaje condensado de monumentos reales e imaginarios, de sitios que existen y otros figurados por el arte y la arquitectura; como lugar de valores puramente arquitectónicos. Las formas representadas aparecen como escenas fijadas, dotadas del poder de evocar ficciones importantes de esta ciudad. Funcionan como figuras metonímicas en las que la parte remite al todo:

An «analogous city» text, not quite a real city not entirely a fictitious one, is a composition of images produced by two kinds of generators: concrete images drawn from a memory archive of architectural types, or imaginary figures and archaic symbols retrieved from deep structure of memory (Boyer 1998: 32-33).

Estas observaciones centradas en las artes plásticas $\mathrm{y}$, en particular, en la arquitectura y la pintura, son válidas también para la literatura, teniendo en cuenta las particularidades de este modo de representación.

Una parte importante de la ficción nace en la ciudad y hace de ella su tema. En la medida en la que se transforma el espacio, se transforman también las modalidades lingüísticas que hablan de éste: la palabra, la escritura. El periodo histórico que marca el inicio de la Revolución Industrial condujo al desarrollo de las grandes ciudades de la modernidad, etapa que coincide con una crisis de la representación en el marco de la ficción narrativa, en el doble plano de lo representado y de las opciones enunciativas (Dugast 1993: 10). A la integridad que caracterizaba el espacio urbano en la escritura de Balzac, por ejemplo, le suceden espacios discontinuos, fragmentarios, heterogéneos $\mathrm{y}$ dispersos. El concepto que mejor simboliza esta nueva situación es la encrucijada, como las de Berlin Alexanderplatz de Alexander Döblin o la de Manhattan Transfer de John Dos Passos. El entrecruzamiento de lenguajes y códigos en el marco de la ciudad moderna -que toma la forma de un super-significado- se corresponde con una escritura que pone en peligro hasta la legibilidad del texto. El lenguaje de la ficción percibe, representa e inventa la ciudad y los lenguajes.

Para revelar los secretos de elaboración de tal modo de percibir, representar e inventar se podría hacer un estudio sociológico del espacio urbano a partir de la literatura. Nuestra intención no es la de usar la obra literaria como medio de interpretación o ejemplo de una realidad externa y preexistente, sino la de cotejar esa otra realidad que la obra revela (o crea), que se impone sobre lo conocido para darle nuevos significados. Esa ciudad que «en tanto referente trastocado por complejos procesos de transformación, reclama un acercamiento no lineal sino una inscripción abierta a un campo de figuración multidimensional, que no se deja compactar al modo de un escenario estético» (Ferro 1998: 43).

Más allá del aspecto formal y geográfico de la ciudad, que puede ser objeto de un proyecto descriptivo en una narración, está también la vida urbana, la cotidianeidad y la mentalidad que penetran el sistema de la representación literaria. El concepto de «ciudad análoga» se podría entender en un sentido más amplio, como el encuentro de las imágenes de un contexto sociohistórico concreto con figuras imaginarias, estructuras de una memoria profunda o de una intuición que este contexto evoca en el sujeto de la percepción. El objeto representado, sin que sus rasgos objetivos o su alma se alteren, adquiere dimensiones de un universo inédito hecho de vestigios e imágenes incoherentes, a veces hasta incompatibles, sacadas del depósito indefinido de la memoria colectiva.

This system of assembling -really reassemblingincompatible city images searches through the deep layers of a city's fabric for unconscious and absent figures pressing to be expressed, images drawn from a meta-encyclopaedia or meta-guidebook that create nodes of turbulence and entanglement (Boyer 1998: 189). 
La imagen de la ciudad, pictórica o literaria, sea cual fuere su grado de «realismo», es siempre una abstracción, una figura imaginada, el resultado de un orden espacial que, establecido por medio del discurso, se convierte en un medio de percibir el entorno. Esta relación compleja entre el espacio y su representación crea la necesidad de centrarse no en la estructuración de los signos que producen la imitación del espacio real, sino en el lenguaje original que nos permite imaginar este espacio.

La ciudad fundada por la escritura surge en el intersticio entre presente y pasado, entre materia y palabra. Dicho de otro modo: «La fundación de la ciudad por la escritura [...] supone una amputación, un olvido, la fundación sólo es posible como acto concreto si la letra significa invención y ausencia, expandiéndose en la red innumerable de remisiones significantes>> (Ferro 1998: 18). Esta distancia entre la autoridad del referente y la representación es la que da la posibilidad de múltiples lecturas, la proyección de espacios de invención variados, el establecimiento de una serie de juegos de figuración discursiva y el desarrollo de toda una retórica; este sistema de figuras -en el sentido que lo entiende Gennette, como la forma del intervalo entre lo pensado y lo escrito-, las múltiples maneras de contar la ciudad centran el interés de este trabajo.

\section{El contexto del Río de la Plata}

El fenómeno urbano ha sido una de las preocupaciones principales de la literatura rioplatense a partir de finales del siglo XIX. Poesía, novela, ensayo y teatro buscaron articular el alma de la metrópoli desde distintos puntos de vista. La zona del Río de la Plata en las primeras décadas del siglo XX es la imagen de una modernidad urbana en plena expansión. Una serie de factores históricos, geográficos y políticos contribuyeron a la transformación de esa ciudad colonial de aire más bien provinciano, en un espacio metropolitano. Esta transformación en sí misma fue tema de narración o, de manera menos directa, constituyó el trasfondo de una literatura urbana.
Los distintos géneros literarios definieron sus formas respectivas a partir de la representación de la ciudad que rápidamente adquirió un aire mítico. Tal vez porque rápidamente se convirtió en una ciudad agresiva, o porque fue el centro de las decisiones administrativas o tal vez porque se la comparaba con las gloriosas capitales europeas, París y Roma, aunque no se poseyera el bagaje histórico que justificara tal comparación.

¿Será porque se puso difícil y vivir en ella fue un privilegio? Pero no, deber ser porque de ella salían las decisiones o quizás porque fue el depósito de los sueños de grandeza de algunos iluminados [...] o la posibilidad de una utopía flotante emparentada con la de Atenas o Roma imperiales o con una ciudad de Dios levantada desde la nada em una planicie incesante, o con las dramáticas ciudades de la cultura industrial a partir de una inmigración que no sólo la cambió sino que saturó esa calles con gritos y fachadas, de peregrinos recuerdos de identidades abandonadas, de nostalgias sin objeto. Viendo las cosas así, Buenos Aires fue la suma de lo que no habría sido de otras ciudades tal vez ni siquiera conocidas, Barcelona sí, París y Londres sí, pero también Yokohama, Cracovia, Compostela o Sassari (Jitrik 1993: 34).

En el ámbito literario, los años veinte estuvieron marcados por a irrupción de la escritura vanguardista -los grupos de Boedo y Florida determinaron dos tendencias distintas, dos topónimos urbanos y a la vez dos maneras distintas de «leer» la ciudad- en detrimento de formas de escritura más tradicionales como el costumbrismo. Es el período de entreguerras, que coincide con el cambio definitivo de Buenos Aires, cuando la ciudad criolla se convierte en metrópoli moderna. El fenómeno de los masivos flujos migratorios desempeñó un papel determinante en la emergencia del nuevo rostro de la ciudad que, a causa de cambios no sólo en términos de cantidad de la población, sino también en términos cualitativos, ya no tuvo nada que ver con el del siglo XIX. Como señala José Luis Romero, en las ciudades donde se produjo una gran concentración de grupos inmigrantes, el cambio consistió también en la sustitución de una sociedad ordenada y compacta por otra, escindida, en el marco de la cual se yuxtaponían dos mundos diferentes. 
Una fue la sociedad tradicional, compuesta de clases y grupos articulados, cuyas tensiones y cuyas formas de vida transcurrían dentro de un sistema convenido de normas: era pues una sociedad normalizada. La otra fue el grupo inmigrante, constituido por personas aisladas que convergían en la ciudad, que sólo en ella alcanzaban un primer vínculo por esa sola coincidencia, y que como grupo carecía de todo vínculo $y$, en consecuencia, de todo sistema de nomas: era una sociedad anómica instalada precariamente al lado de la otra como un grupo marginal (Romero 1976: 331).

Paralelamente a los cambios sociales, el nuevo paisaje metropolitano sufrió rápidas modificaciones impuestas por la industria y a técnica, en el marco de un proceso de modernización acelerada. Estas mutaciones indujeron, inevitablemente a una pérdida de los puntos de referencia tradicionales de la ciudad. "Le vieux Paris n'est plus/ La forme d'une villel change plus vite, hélas! Que le cœur d'un mortel>: los célebres versos de Baudelaire escritos en el contexto de la revolución haussmaniana de la que surge el París de hoy, son perfectamente válidos en el contexto de la metamorfosis que conoció la Buenos Aires de principio de siglo. Se puede verificar una verdadera conmoción en el ámbito de las relaciones sociales y económicas, del perfil urbano, del plano y la perspectiva del paisaje, pero también $y$, ante todo, de la manera de ser, de los comportamientos individuales y de las lógicas institucionales. Tales cambios bruscos y espectaculares contribuyeron a la creación de una dinámica urbana excepcional, con respecto a otras ciudades de América Latina. En esta metrópoli que emergía velozmente surgieron una serie de situaciones y un imaginario que, algunas décadas más tarde, serían los de todas las grandes ciudades modernas en general.

La modernidad urbana de Buenos Aires no es la de Londres, París, Roma o Atenas. La memoria urbana de Buenos Aires es mucho más joven que la de cualquier capital del viejo mundo. En el espacio americano, marcado por el imaginario de la utopía, la ciudad adquiere el perfil de un lugar abierto a todas las innovaciones y transformaciones, un tipo de tabula rasa, lugar para conquistar que, en términos al menos simbólicos, da cabida a todo tipo de transformaciones e invenciones sin el peso de tradiciones preexistentes. En este lugar, la exageración y la extravagancia se convierten en regla.

La Buenos Aires de los años veinte surge como una ciudad de cemento que crece y se extiende a un ritmo desenfrenado, amenazando no sólo las tradiciones locales sino, más profundamente, la integridad psicológica del individuo que se transforma de repente en hombre de masas dentro de una ciudad masificada, en una fracción de la sociedad o en pieza de máquina.

La población se multiplica por doce en sesenta años (de 1869 a 1930). La joven capital entra rápidamente en crisis y se convierte en una ciudad «excusable mais insupportable»-como dice Le Corbusier en su visita del año 1929, una ciudad a la que se califica de extranjera, impersonal, inmoral, inaccesible. Ésta es la gran escena latinoamericana de una cultura de mezcla. Las inmensas cantidades de inmigrantes modifican radicalmente el modo de vida, la manera de hablar, las costumbres, a alimentación, la ideología de los porteños y componen la versión latinoamericana del melting-pot: «modernidad europea y diferencia rioplatense, aceleración y angustia, tradicionalismo $y$ espíritu renovador; criollismo y vanguardia»> (Sarlo 1999 [1988]: 15). La capital argentina de los años treinta olvidó rápidamente su pasado rural y los valores tradicionales. La tensión entre ciudad y provincia alrededor de la que giraban textos como La Gran Aldea de L.V. López o los Cambaceres pierde parte de su actualidad en esa ciudad masificada, turbulenta e inestable con valores morales determinados por los cambios económicos ${ }^{2}$.

2 A pesar de todo, el éxito de una novela como Don Segundo Sombra por esos mismos años (1926) demuestra la persistencia, al menos soterrada, del ámbito del campo y de lo criollo en el imaginario argentino 
El universo ficcional en el que se desarrollan las obras de Roberto Arlt y Juan Carlos Onetti es justamente el de la zona geográfica que delimitan Buenos Aires y Montevideo. La presencia del puerto, de los grandes ejes urbanos, las alusiones a la vida miserable de los que viven en los conventillos o las pensiones -elementos presentes en ambos autores-, sirven de brújula al lector que busca puntos de referencia cronológicos o históricos, aunque sus obras van más allá de una literatura de color local y alcanzan, de manera a veces premonitoria, cuestiones de carácter universal. El individuo agobiado en el marco de una sociedad hostil y miserable, sin valores, se transforma en un ser solitario replegado en un mundo de imaginación -mitos, sueños, escritura-, con la esperanza de encontrar, milagrosamente, una respuesta a su angustia existencial. La búsqueda de la salvación, paralela a la de la identidad, moviliza mecanismos compensatorios destinados a llenar las carencias de la vida cotidiana o a una actitud de ruptura y de transgresión por medio de la cual el individuo se entrega a los excesos, el vértigo, la violencia y los impulsos más allá de todo límite.

Las obras estudiadas en este trabajo recurren a medios de expresión que están en consonancia con la escena literaria mundial, participan plenamente de la modernidad literaria e influyen en su trayectoria. La problemática existencia del yo y su experiencia de la realidad urbana moderna, la búsqueda de una solución como asunto individual -el sitio preponderante que ocupa la subjetividad y la percepción subjetivaacercan directamente las obras de estos dos autores rioplatenses a las de sus contemporáneos: Faulkner, Dos Passos, Céline y Malraux; también a Dostoievski, el expresionismo alemán y el futurismo italiano. Tanto Arlt como Onetti eran grandes lectores de textos múltiples $\mathrm{y}$ variados. En Arlt, aparte de las huellas del autor ruso, se perciben también los ecos del folletín, Rocambole entre otros, de la picaresca española y de otros conocimientos: el saber técnico y los manuales de inventor, el cine, el periodismo, la actualidad, el ocultismo, la magia, la Primera Guerra y la escena política mundial. En Onetti, más joven que Arlt, más cerca de la Segunda
Guerra, cuyo eco aparece de manera soterrada en sus escritos, se nota la influencia de los autores norteamericanos y la escritura cinematográfica que ellos han incorporado en su obra ficcional.

Ninguno de los dos puede clasificar ni encerrar en reglas o corrientes literarias fijas, ambos tuvieron actitudes rebeldes o antiliterarias e incluso abiertamente provocadoras, como en el caso de los artículos de Onetti en Marcha o en la introducción de Los Lanzallamas de Arlt. Autodidactas y de oficios variados, ambos pasaron por la etapa del periodismo. A la manera de Jack London, se sitúan en las antípodas de lo que convencionalmente se podría llamar un « homme des lettres» $\mathrm{O}$ «intelectual»,

En el marco del paisaje literario de la Argentina de los años veinte y treinta, Arlt se podría caracterizar como «vanguardista heterodoxo» (Herrera 1997). A diferencia de una vanguardia que rechaza explícitamente la representación realista y busca fundar un mundo autónomo y completamente separado de la realidad, la escritura de Arlt toma el camino de una relación más ambigua que la negación del mundo real. Es una escritura que no aspira a la reproducción fiel del mundo exterior pero que acepta como inevitable el carácter textual y lingüístico de la realidad literaria y procede a la fabricación de una realidad ficcional que mantiene con el mundo externo relacione múltiples. Arlt es uno de los autores que utiliza el lenguaje realista para alcanzar un resultado que está lejos de cualquier verosimilitud, como para trazar otro camino hacia lo real. El resultado de una retórica extrema: la hipérbole, la exageración, el imaginario exasperado de las soluciones radicales que conduce a un «sistema de explosiones en cadena» (Sarlo 2000: 2-4). Lo fantástico tiene también su lugar en esta escritura ya que la imaginación se convierte en un contrapunto alucinatorio de la experiencia de lo real.

Más conocido que Arlt fuera de Argentina, Onetti se autodefinía como un «ferviente arltiano»> desde los años treinta. No se lo pude caracterizar como un autor vanguardista, según criterios formales pero su obra no sería 
posible sin la asimilación de las lecciones de la vanguardia, entre otras fuentes. En Onetti, el nudo de la historia se encuentra siempre en los intersticios, en lo no dicho, en lo omitido. El relato presenta casi siempre rasgos de una autorreferencialidad y se transforma en un espacio que cuestiona hasta el mismo acto de escribir, lo que es un ataque contra todo lenguaje narrativo que evite autocuestionarse. La imaginación y, por consiguiente, la ficción, aparece como medio de corregir la vida real, que no es sino un pálido esbozo de la «verdadera» vida que, como sabemos desde Rimbaud, no existe. Si la vida no es un sueño, podría ser por lo menos un ensueño.

\section{Buenos Aires y el trasfondo de una afinidad}

Una observación recurrente en los manuales de historia de la literatura hispanoamericana es la influencia de Roberto Arlt en las generaciones posteriores en general y sobre Onetti en particular. Sin embargo, como señalan Maryse Renaud y Rose Corral, la relación entre estas dos escrituras es una cuestión que no ha sido suficientemente estudiada. Estas mismas autoras han tratado el tema en breves ensayos destacando elementos como la violencia, la agresividad, el anticonformismo, la transgresión del buen gusto, de la moral, y también de la frontera entre los géneros literarios, la abundancia de anotaciones agrias, algunos indicios de sadomasoquismo, el juego de impulsos, pasiones e instintos abyectos y también la hábil utilización de metáforas que combinan la agresividad geométrica del mundo urbano con la violencia de instintos sexuales frustrados ${ }^{3}$.

Más allá de los datos geográficos e históricos, los personajes marginales y cierta resonancia de autores europeos y norteamericanos, en el punto de encuentro de la obra de Arlt con la de Onetti, queda todavía por estudiar una multitud de elementos que sería erróneo someter a un único criterio de lectura. En otras palabras, es insuficiente limitar la relación entre los dos autores exclusivamente a la semejanza de los personajes, las descripciones o los ambientes. Se trata más bien de sistemas narrativos que funcionan según lógicas distintas que, no obstante, confluyen hacia una misma concepción del mundo contemporáneo. En las obras de ambos, más allá de analogía, se debería hablar de complementariedad, tanto más vital, cuanto surge de la diferencia.

La elección de las obras que forman el corpus de nuestro estudio se debe a las consideraciones siguientes. Los siete locos y Los lanzallamas (1929, 1931) son la cima de la ficción arltiana. Estamos de acuerdo con Julio Cortázar cuando señala que en el ciclo de Erdosain, el mundo urbano es sofocante y opresor y alcanza dimensiones incomprensibles a las demás narraciones del autor. Cualquier indicio de esperanza desaparece frente a la sensación creciente de estar en un callejón sin salida. La ciudad se revela bajo una multitud de ángulos, perspectivas y discursos interiormente fragmentados y contradictorios sin que sepamos qué perspectiva es la más valida. Entre las calles de Buenos Aires y los pasos de Augusto Remo Erdosain se instala una relación de intensidad particular. En cambio, El juguete rabioso (1926), especie de bildungsroman, con resonancias de la novela picaresca, conserva todavía vislumbres de esperanza. Por otro lado, en El amor brujo el autor vuelve sobre una serie de figuras y técnicas ya conocidas desde Los siete locos y Balder es una versión menos intensa de Erdosain (Cortázar 1981: VII) ${ }^{4}$.

El pozo, Tierra de nadie y los primeros cuentos de Onetti se juntan bajo el signo de la ciudad porteña. Las dos novelas presentan dos aspectos complementarios de un mismo fenómeno -ciudad y alienación- y los relatos agregan una serie de matices. Éstos se caracterizan por un progresivo cambio de tono, inicialmente lúdico

3 Existen pocos trabajos que emprendan un estudio sistemático sobre ambos autores. Entre ellos, la tesis doctoral de R. Perales (1981), los artículos de M. Renaud (1993) y de R. Corral (1992), citados en la bibliografía. 4 Es cierto que también Las aguafuertes de Arlt dan panorama de la vida cotidiana porteña, pero el pacto de lectura en las crónicas periodísticas es distinto del que propone la ficción. 
y, luego, cada vez más sombrío. Desde «Avenida de Mayo...» hasta Tierra de nadie, se podría trazar una línea de graduación en tensión, aislamiento, alienación. Este primer período de Onetti en el que Buenos Aires y la metrópoli ocupan el centro de su mundo ficcional ha sido menos estudiado que el posterior, a partir de La vida breve (1950), que tiene como trasfondo la ciudad imaginaria de Santa María.

Este trabajo se propone a la vez como una lectura de la ciudad -Buenos aires símbolo de la metrópoli-, de la escritura de la ciudad y, al mismo tiempo, emprende una exploración sistemática de los lazos que unen a estos dos autores rioplatenses.

De la introducción del libro, pp. 15-25 


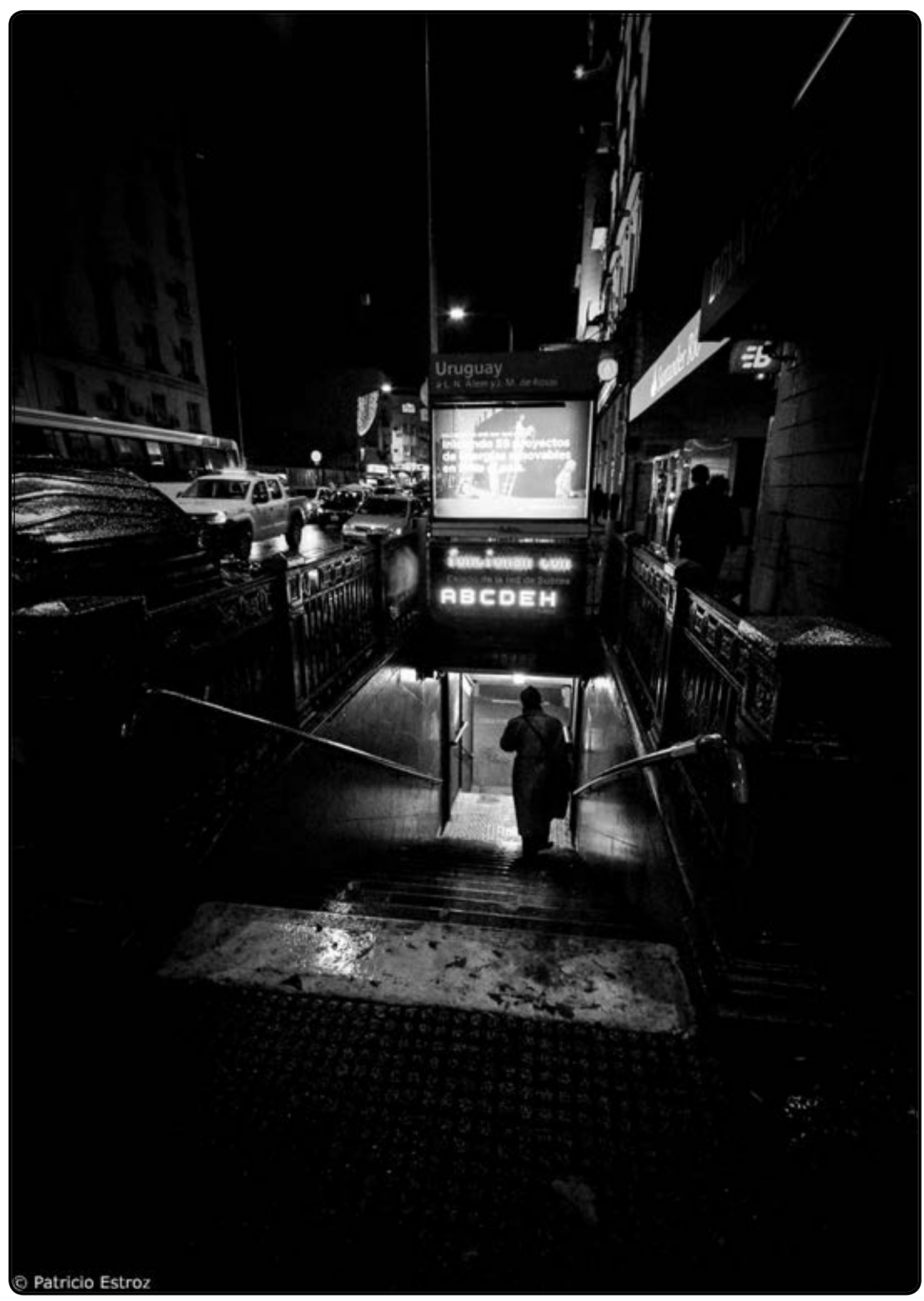

La protección del inframundo. 
